12

\title{
Физическое моделирование процессов формирования повторных ударов отрицательной молнии с использованием искусственных грозовых ячеек
}

\author{
() А.Г. Темников, Л.Л. Черненский, А.В. Орлов, Н.Ю. Лысов, \\ О.С. Белова, Т.К. Кившар, Д.С. Журавкова
}

Национальный исследовательский университет

„Московский энергетический институт“,

Москва, Россия

E-mail: TemnikovAG@mpei.ru

Поступило в Редакцию 25 апреля 2018 г.

Представлены результаты физического моделирования влияния групп крупных модельных гидрометеоров на процессы формирования повторных ударов отрицательной молнии с использованием системы искусственных грозовых ячеек. Впервые показано, что введение группы крупных модельных гидрометеоров в пространство между отрицательно заряженными ячейками существенно увеличивает вероятность формирования повторного разряда, общую длину разрядной системы и величину нейтрализуемого заряда. Установлено влияние гидрометеоров на параметры импульсов тока первого и повторного разрядов. Полученные результаты могут быть использованы при разработке методов искусственного стимулирования формирования многоударной молнии и целенаправленной разрядки грозового облака.

DOI: 10.21883/PJTF.2018.17.46571.17357

Отрицательная нисходящая молния бывает многоударной в 70-80\% случаев [1-4]. При этом механизмы „подключения“ к месту возникновения в грозовом облаке первого главного разряда соседних областей с повышенной плотностью отрицательного заряда (грозовых ячеек) и соответственно формирования повторных разрядов молнии являются одними из наименее исследованных в физике грозы $[1,2,4,5]$. В последние годы все большее внимание уделяется возможному влиянию массивов града на разрядные процессы в грозовом облаке, в том числе на инициирование молнии и общее усиление активности внут- 


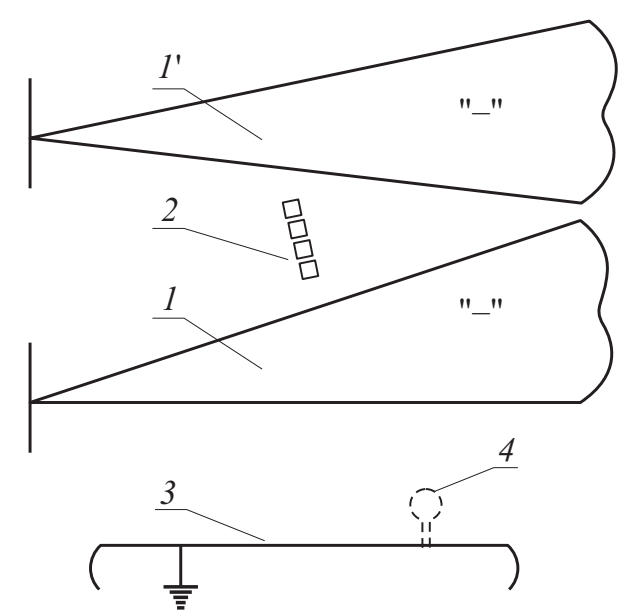

Рис. 1. Расположение группы модельных гидрометеоров в промежутке между отрицательно заряженными искусственными грозовыми ячейками. Пояснения в тексте.

риоблачных молний и молний типа облако-земля [6,7]. Использование отрицательно заряженной ячейки показало, что формирование разряда между ячейкой и землей в редких случаях приводило к формированию повторного разряда с вовлечением областей заряда этой же ячейки, соседних с местом контакта первого разряда с заряженным облаком [8]. При создании системы искусственных грозовых ячеек вероятность формирования повторного разряда между нижней ячейкой и землей по такому сценарию росла, но „подключения“ верхней ячейки к разрядному процессу в случаях, когда заряд верхней ячейки по величине был меньше заряда нижней ячейки, не происходило [9]. Физическое моделирование с использованием системы искусственных грозовых ячеек отрицательной полярности и групп модельных гидрометеоров дает возможность выявить возможное влияние крупных гидрометеоров на процессы формирования многоударной молнии между грозовым облаком и землей и определить перспективные пути целенаправленной разрядки грозового облака путем искусственного провоцирования повторных ударов молнии.

Письма в ЖТФ, 2018, том 44, вып. 17 


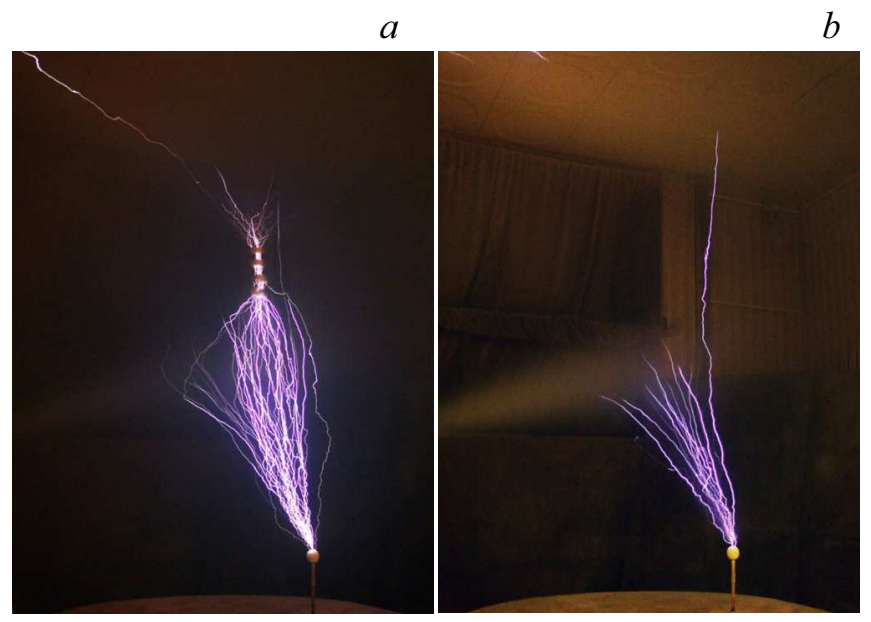

Рис. 2. Характерная картина формирования канальных разрядов между системой отрицательно заряженных ячеек и землей с участием $(a)$ и в отсутствие $(b)$ группы модельных гидрометеоров.

Физическое моделирование процессов формирования повторных ударов отрицательной молнии с использованием системы искусственных грозовых ячеек отрицательной полярности и исследования влияния групп модельных гидрометеоров на инициирование и распространение повторных разрядов были проведены на экспериментальном комплексе, описанном в $[8,10]$. Характерная картина двух искусственных грозовых ячеек 1 и $l^{\prime}$ с расположением между ними группы модельных гидрометеоров 2 показана на рис. 1 . Нижняя ячейка 1 и верхняя ячейка $1^{\prime}$ располагались над поверхностью земли 3 на высотах $0.75-1.2$ и $1.65-2.1 \mathrm{~m}$ соответственно. Под системой отрицательно заряженных искусственных грозовых ячеек на заземленной плоскости устанавливался стержневой электрод 4 со сферической вершиной. Ток первого и повторного разрядов между системой искусственных грозовых ячеек и заземленным стержнем регистрировался цифровым запоминающим осциллографом одновременно с его оптическим и электромагнитным излучением. Экспериментальные исследования в системе верхняя отрицательная искусственная грозовая ячейка-нижняя отрицательная искусственная

Письма в ЖТФ, 2018, том 44, вып. 17 
Таблица 1. Вероятность формирования повторного разряда между системой отрицательно заряженных ячеек и землей (в \%)

\begin{tabular}{c|c|c|c|c}
\hline & \multicolumn{4}{|c}{ Ток выноса нижней ячейки / ток выноса верхней ячейки, $\mu \mathrm{A}$} \\
\cline { 2 - 5 } & $100 /(60-80)$ & $100 /(80-100)$ & $100 /(100-120)$ & $100 /(120-140)$ \\
\cline { 2 - 5 } $\begin{array}{c}\text { В присутствии } \\
\text { гидрометеоров }\end{array}$ & 0.0 & 24.3 & 38.4 & 69.7 \\
$\begin{array}{c}\text { В отсутствие } \\
\text { гидрометеоров }\end{array}$ & 0.0 & 2.2 & 19.1 & 45.4
\end{tabular}

грозовая ячейка-стержневой заземленный электрод были проведены в присутствии и в отсутствие группы модельных гидрометеоров в пространстве между заряженными ячейками. Группа модельных гидрометеоров формировалась из проводящих цилиндров длиной $3.5 \mathrm{~cm}$, расстояние между гидрометеорами в группе составляло $3.0 \mathrm{~cm}$. В течение обеих серий экспериментов заряд нижней ячейки поддерживался на одном уровне (ток выноса генератора заряженного аэрозоля $100 \mu \mathrm{A}$ ). При этом варьировался заряд верхней ячейки через изменение тока выноса генератора заряженного аэрозоля в диапазоне от 60 до $140 \mu \mathrm{A}$ с шагом примерно $20 \mu \mathrm{A}$. Максимальный потенциал системы двух отрицательно заряженных ячеек достигал $1.4 \mathrm{MV}$. Время существования системы искусственных грозовых ячеек при каждом экспериментальном подходе составляло $10 \mathrm{~s}$. Характерная картина формирования канальных разрядов между системой отрицательно заряженных искусственных грозовых ячеек и землей при наличии и отсутствии группы модельных гидрометеоров показана на рис. 2.

Эксперименты показали существенное влияние величины заряда верхней искусственной грозовой ячейки (тока выноса генератора заряженного аэрозоля $\left.I_{\text {outlet }}\right)$ и присутствия массива модельных гидрометеоров между ячейками на вероятность того, что канал первого разряда, сформировавшегося между нижней отрицательно заряженной ячейкой и землей, сможет продолжить свое развитие в пространстве между отрицательно заряженными искусственными грозовыми ячейками, „подключить“ верхнюю ячейку к каналу первого разряда и 
соответственно инициировать формирование повторного разряда между системой отрицательно заряженных ячеек и землей (табл. 1).

Если заряд верхней искусственной грозовой ячейки меньше заряда нижней ячейки, то верхняя ячейка напрямую не участвовала в формировании главной стадии разряда. В отсутствие гидрометеоров канальные разряды формировались только между нижней заряженной ячейкой и землей, практически не выходя за верхние границы нижней ячейки. При наличии модельных гидрометеоров в пространстве между заряженными ячейками в четверти случаев канальные разряды проходили через нижнюю ячейку, доходили до группы гидрометеоров, останавливались и дальше в сторону верхней ячейки не распространялись. Когда заряд верхней ячейки становился больше, чем заряд нижней ячейки, верхняя ячейка начинала напрямую участвовать в формировании повторных разрядов между системой заряженных облаков и землей. В случае присутствия гидрометеоров „подключение“ верхней заряженной ячейки и формирование повторного разряда происходило в $70 \%$ случаев (при отсутствии гидрометеоров эта доля была в $1.5-2.0$ раза меньше). При этом максимальная длина разрядной системы увеличивалась в 9-12 раз относительно линейных размеров самой группы модельных гидрометеоров, участвующих в формировании повторных разрядов.

Анализ и обобщение полученного массива осциллограмм тока главной стадии разрядов, формирующихся с участием обеих искусственных грозовых ячеек отрицательной полярности, выявили два вида импульса тока, характерных для случаев формирования повторных разрядов (рис. 3). Вариант 1 - двойной импульс с длительной паузой между импульсами, в течение которой продолжительный ток имеет средние значения, не превышающие $\sim 1 \mathrm{~A}$ (рис. $3, a$ ). Вариант $2-$ двойной импульс с паузой между импульсами, в течение которой наблюдается явно выраженный продолжительный ток, имеющий в среднем величину 4-8 A (рис. 3, $b$ ). Для экспериментов с наличием гидрометеоров между искусственными грозовыми ячейками регистрировался только первый вид импульсов тока главной стадии разряда. Длительность паузы между импульсами составляла 4-14 $\mu$ s. Второй вид импульсов тока регистрировался для обеих экспериментальных серий (с массивом гидрометеоров между ячейками и без него). Длительность стадии продолжительного тока между импульсами в этом случае не превышала $2-3 \mu \mathrm{s}$.

Письма в ЖТФ, 2018, том 44, вып. 17 

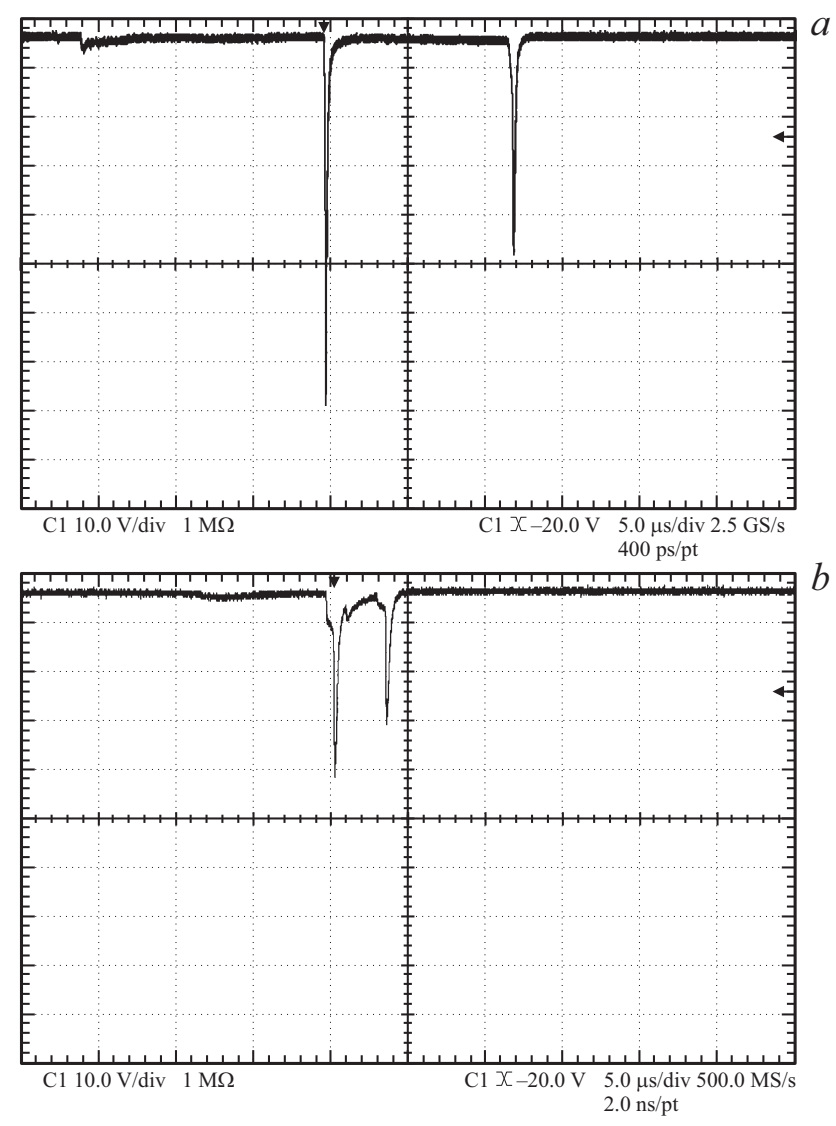

Рис. 3. Характерные осциллограммы токов первого и повторного разряда между системой отрицательно заряженных ячеек и землей с участием $(a)$ и в отсутствие $(b)$ группы модельных гидрометеоров.

Установлено существенное различие между параметрами импульсов тока первого и повторного разрядов (табл. 2). Амплитуда первого импульса тока в двух ударных разрядах между системой отрицательно заряженных ячеек и землей при участии массива гидрометеоров в пространстве между ячейками в среднем была в $1.4-2.2$ раза больше 
Таблица 2. Параметры импульсов тока (средние значения) первого и повторного разрядов между системой отрицательно заряженных ячеек и землей (вариант 1/ вариант 2)

\begin{tabular}{|c|c|c|c|c|}
\hline \multirow[b]{3}{*}{$\begin{array}{l}\text { В присутствии } \\
\text { гидрометеоров }\end{array}$} & \multicolumn{2}{|c|}{ Амплитуда импульса тока, А } & \multicolumn{2}{|c|}{ Импульсный заряд, $\mu \mathrm{C}$} \\
\hline & $\begin{array}{c}\text { Первый } \\
\text { разряд }\end{array}$ & $\begin{array}{c}\text { Повторный } \\
\text { разряд }\end{array}$ & $\begin{array}{c}\text { Первый } \\
\text { разряд }\end{array}$ & $\begin{array}{c}\text { Повторный } \\
\text { разряд }\end{array}$ \\
\hline & $75.3 / 57.4$ & $33.4 / 39.6$ & $17.5 / 14.7$ & $15.3 / 16.2$ \\
\hline $\begin{array}{c}\text { В отсутствие } \\
\text { гидрометеоров }\end{array}$ & $-/ 41.9$ & $-/ 40.2$ & $-/ 7.1$ & $-/ 15.1$ \\
\hline
\end{tabular}

амплитуды импульса тока повторного разряда. Только менее чем в $9 \%$ случаев амплитуда второго импульса тока была больше, чем амплитуда первого импульса. Это коррелирует с данными [3], показывающими, что обычно амплитуда тока первого главного разряда молнии в 2-3 раза выше, чем амплитуды тока последующих разрядов, и приблизительно в 7\% случаев повторные разряды имеют бо́льшую амплитуду тока, чем первый удар. В отсутствие модельных гидрометеоров такой связи между импульсами тока в двух ударных разрядах не наблюдалось. Эксперименты показали, что импульсные заряды первого и повторного разрядов, формирующихся между отрицательно заряженными ячейками и землей с участием группы гидрометеоров, близки по величине. При этом суммарный заряд, нейтрализуемый в двух ударных разрядах, в среднем был в 1.5 раза больше, чем в случае отсутствия гидрометеоров в промежутке между ячейками.

Таким образом, присутствие массивов крупных гидрометеоров (града) в отрицательно заряженной части грозового облака может существенно увеличить вероятность формирования повторных разрядов молнии в землю, например стимулируя развитие в нем возвратных стримеров и отрицательных лидеров $[4,5]$.

Исследование выполнено за счет гранта Российского научного фонда (проект № 16-19-00160).

Письма в ЖТФ, 2018, том 44, вып. 17 


\section{Список литературы}

[1] Базелян Э.М., Райзер Ю.П. Физика молнии и молниезащиты. М.: ФИЗМАТЛИТ, 2001. $320 \mathrm{c.}$

[2] Rakov V.A., Uman M.A. Lightning: physics and effects. Cambridge University Press, 2003. 687 p.

[3] Lightning parameters for engineering applications. CIGRÉ. 2013. Techn. Bull. 549.

[4] Dwyer J.R., Uman V.A. // Phys. Rep. 2014. V. 534. P. 147-241.

[5] Mazur V. Principles of lightning physics. IOP Publ., Ltd, 2016. 182 p.

[6] Emersic C., Heinsel P.L., MacGorman D.R., Bruning E.C. // Monthly Weather Rev. 2011. V. 139. P. 1809-1824.

[7] Wang F., Zhang Y., Zheng D., Xu L., Zhang W., Meng Q. // J. Meteorol. Res. 2017. V. 31. N 5. P. 976-986.

[8] Temnikov A.G. // 2012. Int. Conf. on lightning protection (ICLP). IEEE Conf. Publ., 2012. DOI: 10.1109/ICLP. 2012. 6344279

[9] Temnikov A.G. // Elect. Power Syst. Res. 2014. V. 113. P. 3-9.

[10] Темников А.Г., Черненский Л.Л., Орлов А.В., Лысов Н.Ю., Белова О.С., Калугина И.Е., Герастенок Т.К., Журавкова Д.С. // Письма в ЖТФ. 2017. T. 43. B. 4. C. $32-38$. 